\title{
AN EVALUATION OF THE EFFECTIVENESS OF THE GRANARY AREA PROGRAMME
}

\author{
GKDS Gunasekara \\ Ministry of Agriculture, Battaramulla, Sri Lanka
}

Accepted: $7^{\text {th }}$ October 2009

\begin{abstract}
The Granary Area Programme (GAP) was designed to enhance the productivity of rice farming in areas with high potential for rice cultivation in Sri Lanka. The purpose of this study was to assess the impacts of the programme interventions. The findings of this study suggest that this programme was unable to make a significant contribution to productivity enhancement in the paddy sector and to increase the farmers' adaptability to new agronomic practices. However, the GAP has contributed to the development of the extension system.
\end{abstract}

Key words: Extension, Farmer Groups, Granary Area programme, Rice

\section{INTRODUCTION}

The GAP was implemented by the Ministry of Agriculture (MOA) and the Ministry of Irrigation (MOI) as a participatory approach to extension, targeting rice producing farmer groups in areas of high potential for rice production. The GAP was started in 2003 and implemented in seven distinct major irrigation regions which are referred as Granary areas until the end of 2007. This programme was expected to include 2,670,000 ha of paddy lands across the country (MOA and MOI 2003). To conduct an in-depth investigation of the programme, the command area of Weerawila reservoir in Hambantota district that covers approximately 800 ha of paddy lands was selected as the case study area.

The objective of the study is to assess the impact of the Granary Area programme. Achieving this objective, the level of productivity improvement of paddy cultivation and the level of adoption of new agronomic practices among programme participants as a result of the programme and its influence for the development of the agriculture extension system were assessed. The philosophical orientation of this research mainly belongs to the Constructivism (Guba and Lincoln 1994) and therefore, the various perceptions of different stakeholders at all programme levels were taken into consideration in this study. Modified Bennet's Hierarchy framework (Coutts 2005) was adopted to develop a research framework for this study. The data collection was based on both qualitative and quantitative approaches. First, data were collected from the case study level from both GAP and non-GAP farmers, and from the extension staff through semistructured interviews. Then the quasi-experimental approach was employed and the information was gathered through a structured questionnaire from both types of farmers ( 35 from each type). In addi- tion to primary data, the secondary data were also used in this study.

The impact of GAP to improve the productivity of paddy cultivation:

The yield information that was collected from both GAP and non-GAP farmers for three years using the structured questionnaire indicate that there has been a gradual increase in the average paddy yield during recent years. According to the survey results regarding the farmers' perception on the reasons for the yield increases, all the informants of both types suggested the reasons were low fertilizer prices, automatic addition of straw to the fields when machine harvesting and higher paddy prices.

The findings of the survey were also supported by the results of the semi-structured interviews conducted with both types of farmers in the case study area. Based on the information from the survey, the following graph was plotted to compare the yield variations between the GAP and non-GAP farmers. This figure shows that there is no significant difference in the yield between the both types of farmers in the case study area. These findings concur with the results of the research undertaken by Udaya-

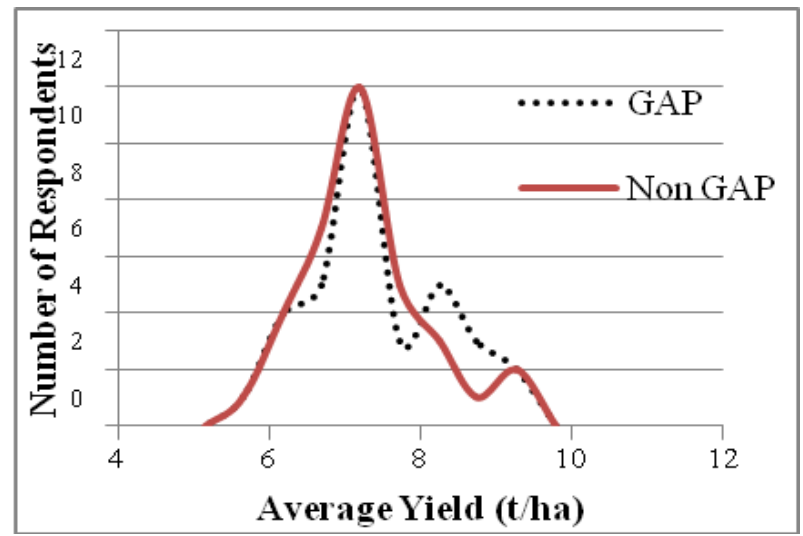

Figure 1: Yield variations of the GAP and non-GAP farmers in 2007

\footnotetext{
*Corresponding author:shyamalee2003@yahoo.com

Paper presented at the $2^{\text {nd }}$ National Symposium, Faculty of Agriculture, University of Ruhuna
} 
naganie (2004) who posits that there is no significant impact of the GAP on increasing the paddy yields. However, this assumption contradicts the findings of other previous studies, which found significant yield variations between the GAP and nonGAP farmers (Gallage 2006; DOA 2005; 2006a).

All information sources suggested that paddy yield increased remarkably during the programme period. However, the field information suggests that rather than being the result of interventions of the GAP, the main reasons for yield increase were the decrease of fertilizer prices and the popularization of mechanized harvesting. Furthermore a marked increase of paddy yield for the GAP farmers over the non-GAP farmers was not able to be identified.

\section{Adaptability to improved agronomic practices:}

The data on organic matter application to the paddy fields by both GAP and non-GAP farmers were compared. The table 1 illustrates these results. This information suggests that the majority of the farmers apply rice straw to their fields. However it was revealed that the reason for the high use of rice straw is recent adaptation of the use of combine harvesters. It also shows a slight increase of organic matter application among GAP farmers over nonGAP farmers.

The Knowledge, Attitude, Skills, Aspirations and Practice (KASAP) of organic matter application for paddy cultivation were explored with both types of farmers and the figure 2 represents this information. This graph shows that there is a substantial gap between the knowledge and the practice of organic matter application for both types of farmers. The majority of the farmers said that, "Yes, we know about the importance of organic matter application, but it is not practical for us to apply a heap of organic matter to a large paddy field. We use the available organic matter for vegetable cultivation or home gardening". The graph also shows that the knowledge gap is wider between the two groups but that this gap gradually narrows with the actual practice of application. Therefore, it can be assumed that the GAP has a positive impact on in-

Table 1: Difference of organic matter application and methods of pest control in paddy cultivation

\begin{tabular}{llll}
\hline Criteria & Method & \multicolumn{2}{l}{ No. of Farmers } \\
& & GAP & Non GAP \\
\hline Organic Matter & Rice straw & 35 & 33 \\
Application & Charred Rice Husk & 04 & 02 \\
& Cow dung & 03 & 03 \\
& Fodder (Gliricidia) & 06 & 04 \\
\multirow{2}{*}{ Method of pest } & Use of pesticide & 22 & 24 \\
control & Not using pesticide & 04 & 03 \\
& IPM approach & 09 & 08 \\
\hline
\end{tabular}

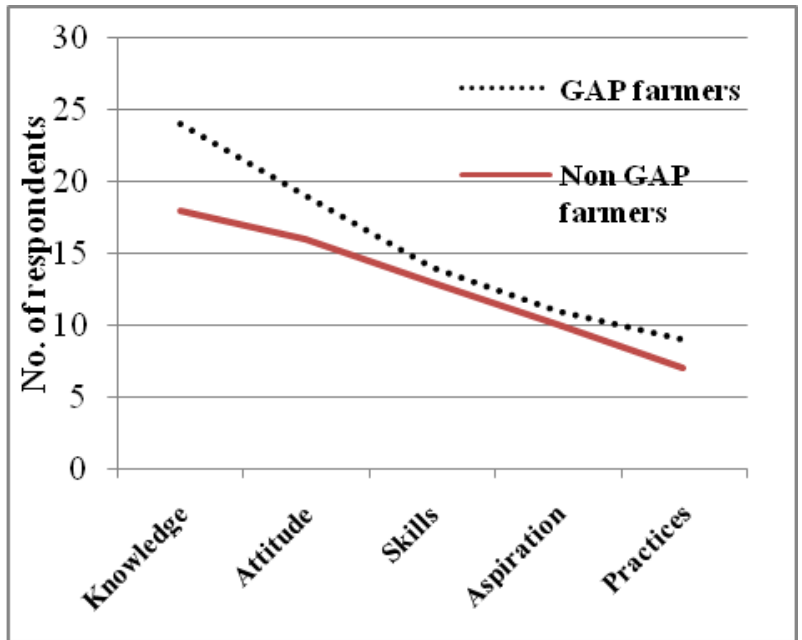

Figure 2: KASAP changes of organic matter application in paddy farming

creasing the knowledge of organic matter application among GAP farmers rather than the actual practice.

Practicing an Integrated Pest Management (IPM) approach is a key component of the GAP. During the semi-structured interviews, it was not possible to find any farmer of either type who used IPM methods to control pests in paddy cultivation. However, based on the survey results, the table 1 provided the information regarding the use of various pest control methods. Only nearly $25 \%$ of the farmers of the both types said that they did use IPM practices. This information shows that there is no clear relationship between IPM and the GAP in the case study area. This finding resonates with Gallage (2006) who found that there is no significant impact of the GAP on the adoption of IPM practices. However, as has been found in previous sections, the internal evaluation of the GAP (DOA 2005, 2006b) found contradicting results regarding the use of IPM and reported a more than $50 \%$ increase in IPM practice among GAP farmers compared with non-GAP farmers.

The survey results regarding the KASAP changes of the IPM approach in the study area suggest that there is a reasonable gap between the knowledge of IPM similar to what was found with the organic matter application. The GAP framers have a higher knowledge of IPM practices than the

Table 2: Methods of getting extension service of the GAP

\begin{tabular}{lll}
\hline Method & GAP & Non-GAP \\
\hline Farmers visit AI & 20 & 25 \\
AI visit farmers & 11 & 02 \\
AI visit farmer groups & 09 & - \\
Via telephone & 07 & 02 \\
\hline
\end{tabular}


non-GAP farmers and there is no difference in the practice of IPM between these two groups.

The findings show that the majority of farmers are aware of new technology, but their adaptability to it is low. However, it appears that the knowledge of GAP farmers regarding the new agronomic practices is slightly higher than that of the non-GAP farmers. Further, the results show that there is no remarkable impact of these GAP interventions in improving the farming practices of the paddy farmers. The results also reveal that impacts of other external factors would be more significant on many occasions than the impact of the GAP interventions.

\section{Influence of the GAP in developing the agricul- tural extension system:}

The survey information shows that participation of the GAP farmers in extension training is much higher than for the non-GAP farmers. Also the results of the interviews show that there is a strong relationship between farmer groups and the field extension staff. The table 2 summarizes the methods of receiving extension services and provides further evidence for this view. The GAP farmers commented that they received the AIs' (Agriculture Instructors) assistance when needed. This situation is more common among GAP farmers than nonGAP farmers. The reason for this may also be due to their better established relationship with the AIs.

The response of the field extension staff revealed that the approach of the GAP has motivated them to perform better. All the AIs of the Weerawila region commented that their recognition within the farming community has increased as a result of the GAP. The responses of GAP farmers regarding the service of the field extension staff reinforced this finding. The semi-structured interviews revealed that the AIs do not receive any additional incentives or travelling allowance for implementing this programme. However even without any financial benifit, the general view of the field extension staff was that this programme should be further expanded. This information reveals that this programme has impacted to strengthen the extension system.

Finally, it is important to emphasize that this study is based on research conducted in a single case study area. Where possible and within the researcher's capacity, multiple perspectives were taken into consideration. However it would not be appropriate to generalize the findings of this case study across the entire programme. While there have been interesting lessons drawn from this case study, it points to the need for further research with multiple case study areas.

\section{REFERENCES}

Coutts J 2005 'Evaluating Success in Achieving Adoption of New Technologies', DPI and Beef CRC conference: moving from Research to Adoption, Quality Nautilus Resort, Coffs Harbour, NSW, Australia, 3-5 May 2005.

Department of Agriculture 2005 'An Assessment of the Impact of the Granary Area Programme in Polonnaruwa District', Socio-Economics and Planning Centre, Department of Agriculture, Peradeniya, Sri Lanka.

Department of Agriculture 2006a 'Progress of the Granary Area Programme-2006', Extension and Training Division, Department of Agriculture, Peradeniya, Sri Lanka.

Department of Agriculture 2006b 'An assessment of the Impact of the Granary Area Programme in Polonnaruwa, Hambantota \& Anuradhapura Districts in 2005/06 Maha Season', SocioEconomics and Planning Centre, Department of Agriculture, Peradeniya, Sri Lanka.

Gallege RP 2006 'Evaluation of Interventions of the Granary Area Programme at Minneriya Major Irrigation Scheme', Department of Agricultural Economics, University of Ruhuna, Sri Lanka.

Guba, EG and Lincoln YS 1994 'Competing Paradigm in Qualitative Research' in NK Denzin \& YS Lincoln (eds), Handbook of Qualitative Research, Sage Publications, Thousand Oaks, California, USA.

Ministry of Agriculture and Ministry of Irrigation and Water Management 2003 Granary Area Programme, Ministry of Agriculture \& Ministry of Irrigation and Water Management, Colombo, Sri Lanka.

Udayanganie SMS 2004 'Impact of Granary Area Programme on Rice Productivity Improvement at Farmer Level', Department of Agricultural Economics, University of Ruhuna, Sri Lanka. 